\title{
Research Article \\ Effect of Ammonia Fumigation Treatment on Wood Color and Chemical Composition
}

\author{
Weigang Zhang $\mathbb{D}^{1},{ }^{1}$ Minzhen Bao $\mathbb{D}^{2}{ }^{2}$ Weisheng Sun, ${ }^{1}$ Lei Huang, ${ }^{1}$ and Liang Cheng ${ }^{1}$ \\ ${ }^{1}$ School of Engineering, Zhejiang Agricultural and Forestry University, Hangzhou 311300, China \\ ${ }^{2}$ Key Laboratory of High Efficient Processing of Bamboo of Zhejiang Province, China National Bamboo Research Center, \\ Hangzhou 310012, China
}

Correspondence should be addressed to Weigang Zhang; 20091018@zafu.edu.cn and Minzhen Bao; baominzhen@caf.ac.cn

Received 22 February 2021; Accepted 24 March 2021; Published 17 April 2021

Academic Editor: Xian Ai Huang

Copyright ( 2021 Weigang Zhang et al. This is an open access article distributed under the Creative Commons Attribution License, which permits unrestricted use, distribution, and reproduction in any medium, provided the original work is properly cited.

Betula alnoides was used as a test material to study the effect of ammonia fumigation treatment on wood color and chemical composition. The effects of concentration, temperature, and duration of ammonia fumigation on wood color were studied. The properties of the material were studied using contact angle measurements, X-ray diffraction, Fourier-transform infrared spectroscopy, and dynamic thermomechanical analysis. In general, the color difference of the wood increased with the concentration of ammonia used in the fumigation process, treatment temperature, and treatment duration. After ammonia fumigation treatment, the chemical composition of hydroxyl and carboxyl groups in the wood was reduced. We concluded that ammonia fumigation treatment decreased material wettability and dynamic mechanical rigidity and increased the degree of crystallinity in wood.

\section{Introduction}

Owing to its natural appearance, esthetically pleasing color, and excellent material properties, wood is widely used in decorative building applications, particularly for flooring $[1,2]$. Economic development and improved quality of life have increased the demand for more abundant colors and varieties of wood flooring. Antique wood is artistically designed and chemically toned to produce a rich and stable color, strong layering, and visual appeal. The surface is processed in an old-fashioned style [3]. Since the 1970s, European and American countries have used chemical toning to achieve antiquestyle wood flooring and furniture. Chinese flooring companies began to produce antique flooring in the 1990s. Their products quickly captured the domestic market, resulting in the rapid development of antique flooring manufacturing methods.

The ammonia fumigation process uses ammonia and ammonia solution to naturally change the color of the wood surface in a confined space under certain environmental conditions [4]. Pawlak and Pawlak [5] studied the chemical reac- tion between liquid ammonia and wood and found that there may be three chemical reactions between liquid ammonia and wood: (1) ammonia reacts with the carboxyl group to form an amide, (2) ammonia reacts with aldehydes and ketones to form imines, and (3) the ester group reacts with the amide. Research by Weigl et al. [6] showed that ammonia fumigation is effective for preventing the aging of wood and maintaining the color. Weigl also studied the effect of ammonia fumigation on the color of 38 kinds of wood and found that the color change of wood after ammonia fumigation was due to the change of wood chemical composition. Miklečić et al. [7] studied the effect of ammonia on the color change of oak, maple, spruce, and larch wood. All of these woods experienced obvious blackening after exposure to ammonia. Ammonia chemical coloring can reduce unevenness in the color of composite wood in the inplane and thickness directions and can make the wood texture more prominent and esthetically pleasing. Wood subjected to ammonia fumigation acquires a unique color, which enriches the style of the wood and makes full use of wood materials. 
Herein, Betula alnoides was used as a raw material to carry out ammonia fumigation treatment. A single factor experiment was used to study the influence of ammonia fumigation on wood color at different temperatures and concentrations for different durations. Subsequently, the contact angle, crystallinity, and functional groups of the treated material were analyzed. In addition, the dynamic viscoelasticity of the treated material was studied. This research provides a theoretical reference for determining suitable processing and utilization conditions of ammonia fumigation treatment, with the aim of improving wood product quality.

\section{Materials and Methods}

2.1. Preparation of Materials. B. alnoides air-dried sawn timber of good quality and with no obvious defects (cracking, discoloration, or decay) was used as the test material. After planning on all sides, the timber was cut into test pieces with dimensions of $200 \times 40 \times 20 \mathrm{~mm}$. Diluting $28 \%$ ammonia solution with deionized water to obtain $22 \%$ and $16 \%$ ammonia solution. Then, $50 \mathrm{~mL}$ of ammonia solution $(16 \%, 22 \%$, or $28 \%$ ) was placed in a glass dish at the bottom of a container. The test pieces were stacked in the glass dish so as to maximize the contact area between the wood and ammonia. The reaction vessel was then sealed and placed in a blast drying box set to a temperature of 25,30 , or $35^{\circ} \mathrm{C}$. The test conditions were as follows: ammonia concentrations of $16 \%$, $22 \%$, or $28 \%$ at a fixed temperature of $30^{\circ} \mathrm{C}$; and temperatures of 25,30 , or $35^{\circ} \mathrm{C}$ at a fixed ammonia concentration of $28 \%$. For each condition, 15 wood samples were removed on days 1,3 , and 5 to test their performance.

2.2. Color Determination. An automatic colorimeter was used to measure and record the colorimetric parameters of the samples before and after processing. The sample color was measured and calculated based on the $L^{*} a^{*} b^{*}$ chromaticity space color system of CIE (International Illumination Standards Committee). According to the $L^{*} a^{*} b^{*}$ system, the color difference $(\Delta E)$ between two specimens (e.g., before and after processing) is calculated as

$$
\Delta E=\sqrt{\left(\Delta L^{*}\right) 2+\left(\Delta a^{*}\right) 2+\left(\Delta b^{*}\right)^{2}},
$$

where $\Delta L^{*}, \Delta a^{*}$, and $\Delta b^{*}$ represent the total changes in $L^{*}$, $a^{*}$, and $b^{*}$ after the ammonia fumigation treatment, respectively.

2.3. Surface Wettability Analysis. The static drop method was used to measure the contact angle of the wood surface. Distilled water was used as a test liquid. The sample was injected directly during the test. In this experiment, a photograph was taken within 1 to $2 \mathrm{~s}$ of droplet injection, and then the surface contact angle of the wood was measured using the tangent method. Each measurement was repeated 6 times, and the results were averaged.

2.4. X-Ray Diffraction (XRD) Analysis. XRD patterns of the specimens were determined using a Bruker D8 Advance dif-

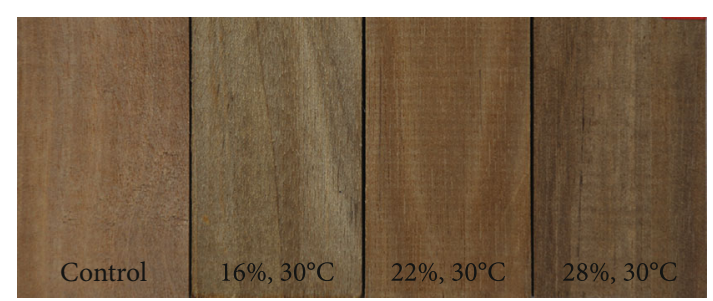

Figure 1: The appearance of the ammonia-fumigated sample at different ammonia concentrations.

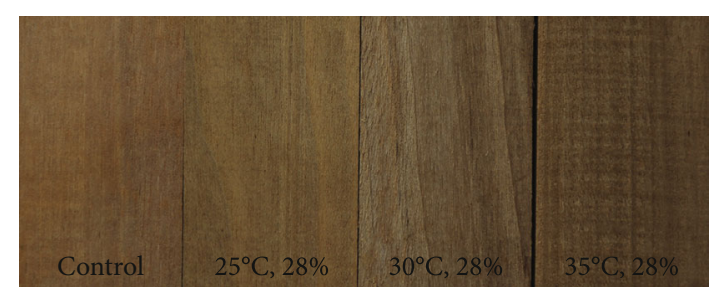

FIgURE 2: The appearance of the ammonia-fumigated samples at different temperatures.

fractometer with $\mathrm{Cu} \mathrm{K} \alpha$ radiation $(\lambda=1.5404 \AA)$ at a scanning rate of $2^{\circ} \mathrm{min}^{-1}$ in the range of $10-80^{\circ}$. Segal et al.'s [8] empirical method was used to calculate the crystallinity. The diffraction intensity of wood fiber has a maximum value of $I_{002}$ when $2 \theta=22^{\circ}$ and a minimum value of $I_{\mathrm{am}}$ when $2 \theta$ $=18^{\circ}$. These intensity values were used to calculate the diffraction scattering intensity of the amorphous area in the wood fiber. The cellulose crystallinity was calculated as

$$
C_{r}=\frac{I_{002}-I_{a m}}{I_{002}} \times 100 \% .
$$

2.5. Dynamic Mechanical Analysis (DMA). Test samples with dimensions of $35 \times 12 \times 2 \mathrm{~mm}$ were prepared for DMA. A test temperature range of $30-260^{\circ} \mathrm{C}$, heating rate of $2^{\circ} \mathrm{C} / \mathrm{min}$, constant strain of $0.02 \%$, and amplitude of $20 \mu \mathrm{m}$ were used. The sample was fixed to a double $35 \mathrm{~mm}$ cantilever beam. The temperature of the sample environment was raised from room temperature to $30^{\circ} \mathrm{C}$, followed by an isothermal hold for $5 \mathrm{~min}$. Subsequently, the temperature program measurement was started. The storage modulus and loss modulus were used as parameters to characterize the dynamic mechanical properties of the material.

2.6. Fourier-Transform Infrared (FTIR) Analysis. Infrared spectra of the samples were obtained from a $\mathrm{KBr}$ disk containing 1\% finely ground samples using a Fourier-transform infrared (FTIR) spectrometer (Vertex 70, Bruker, Japan). Each spectrum was recorded over the wavenumber range of 4000 to $400 \mathrm{~cm}^{-1}$ with an average of 32 scans at a spectral resolution of $4 \mathrm{~cm}^{-1}$.

\section{Results and Discussion}

3.1. Color Change. Figures 1 and 2 showed the appearance of the ammonia-fumigated wood under different treatment conditions. With the increase of the ammonia concentration 


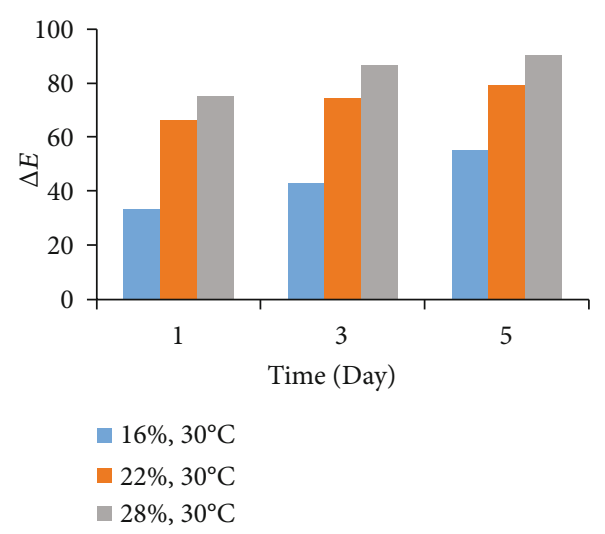

(a)

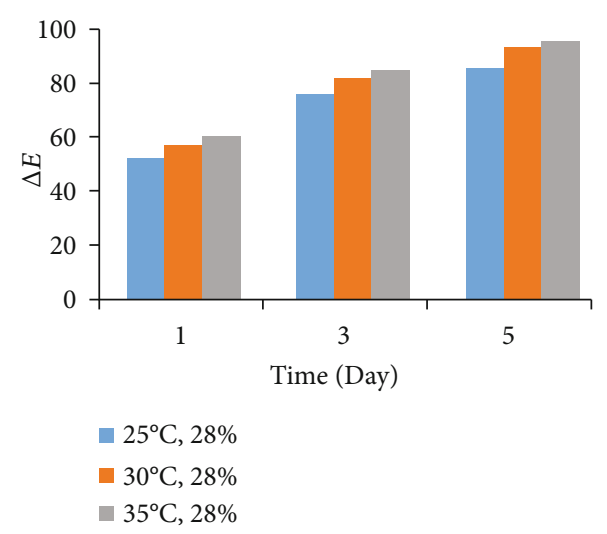

(b)

Figure 3: Total color change $(\Delta E)$ of wood samples. (a) $\Delta E$ of wood samples fumigated at different ammonia concentrations (16-28\%) for different durations (1-5 days); (b) $\Delta E$ of wood samples fumigated at different temperatures (25-35 $\mathrm{C}$ ) for different durations (1-5 days).

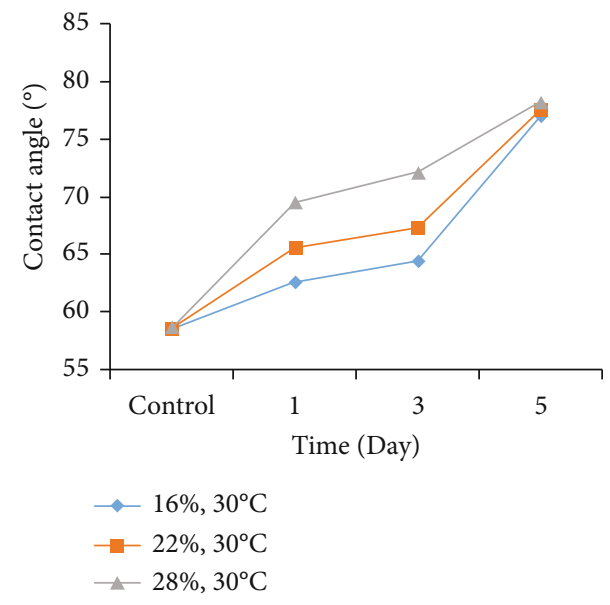

Figure 4: Contact angle of ammonia-fumigated wood samples.

and the fumigation temperature, the color of treated samples gradually deepened.

Figure 3(a) shows the variation in $\Delta E$ of ammoniafumigated samples depending on the ammonia concentration and treatment duration at a temperature of $30^{\circ} \mathrm{C}$, and Figure 3(b) shows the variation in color difference depending on the fumigation temperature and treatment duration at $28 \%$ ammonia solution. As shown in Figure 3, the chromatic aberration of the treated samples increased significantly as the treatment duration increased. The chromatic aberration increased significantly between the first and third days and slightly between the third and fifth days. When the treatment temperature was $30^{\circ} \mathrm{C}$, the $\Delta E$ increased with increasing ammonia concentration. The $\Delta E$ between the samples fumigated in ammonia solution of different concentrations indicated that the ammonia concentration helps to improve the effect of ammonia fumigation. When the ammonia concentration was $28 \%$, the $\Delta E$ increased with increasing temperature. However, the $\Delta E$ at different temperatures indicated that the temperature has a low effect on the color of the ammonia-fumigated wood. The color of wood is mainly derived from the chromophore groups in lignin; in addition, the pigment, tannin, resin, and other substances in the extract also have a significant effect on the color of the wood. According to existing research, the main chemical cause of wood discoloration is the oxidative condensation reaction of tannins, pigments, alkaloids, sugars, phenols, and other organic substances in wood [9]. Under the action of ammonia, the resins, tannins, polyphenols, and anthocyanins in the wood undergo chemical reactions to deepen the color of the wood.

3.2. Surface Wettability. Figure 4 shows the variation in water contact angle of the samples treated at $30^{\circ} \mathrm{C}$ with different ammonia concentrations and treatment durations. Compared with that of the control wood, the contact angle of the ammonia-fumigated samples increased with increasing ammonia concentration and treatment duration. The difference in the contact angle of wood treated with different ammonia concentrations decreased with increasing treatment duration, with a contact angle of approximately $77^{\circ}$ after 5 days of treatment. An increase in contact angle corresponds to a decrease in wettability. The change in contact angle is mainly related to the change of chemical components of the wood after ammonia fumigation. Free radicals on the wood surface react during the ammonia fumigation process. The crystallinity of the ammonia-fumigated wood increases, and the amount of amorphous cellulose and free hydroxyl groups decreases accordingly [10]. Therefore, its surface wettability decreases, resulting in the measured increase in contact angle.

3.3. XRD Analysis. As shown in Figure 5, the positions of the XRD peaks of the wood crystal planes were not significantly different after the ammonia fumigation process. In addition, the width of the crystalline zone did not change significantly; that is, the ammonia fumigation treatment did not change the wood cellulose crystal structure. Ammonia can enter the amorphous regions of cellulose to cause swelling by increasing the distance between the molecular chains, which increases the crystallinity of the wood [11]. Table 1 demonstrates that treatment duration had an obvious effect on the 


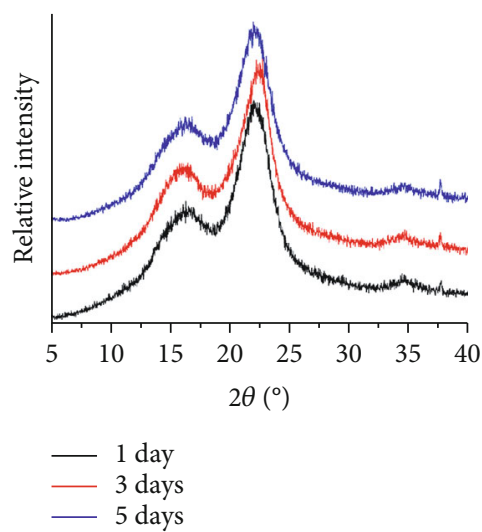

(a)

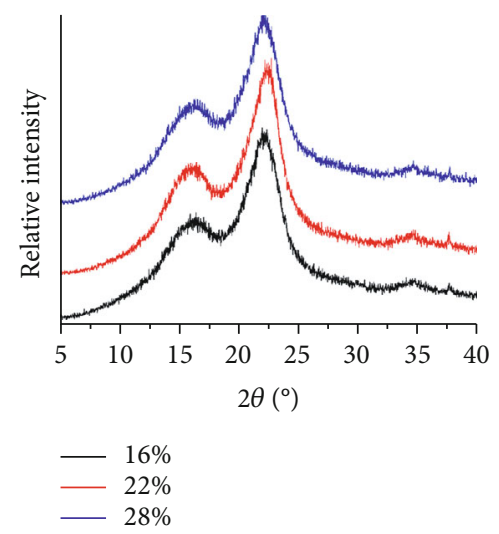

(b)

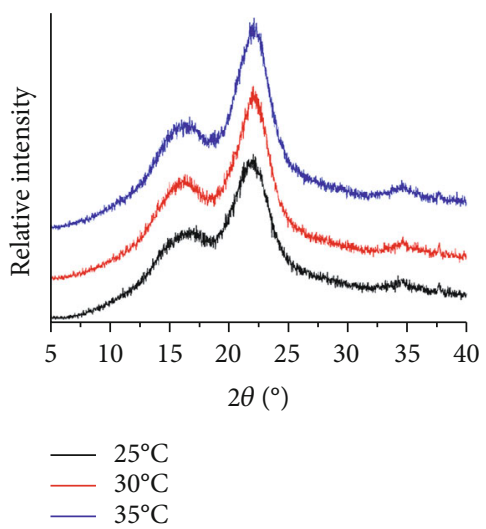

(c)

FIGURE 5: XRD curves of treated wood samples. (a) Durations (1-5 days); (b) ammonia concentrations (16-28\%); (c) temperatures (25-35 ${ }^{\circ} \mathrm{C}$ ).

TABLE 1: Crystallinity of treated wood samples.

\begin{tabular}{lcccc}
\hline Samples & Concentration/\% & Temperature ${ }^{\circ} \mathrm{C}$ & Duration/day & Crystallinity/\% \\
\hline & 22 & 30 & 1 & 54.98 \\
& 16 & 30 & 46.63 & 55.49 \\
& 22 & 30 & 3 & 55.60 \\
Ammonia-fumigated samples & 28 & 30 & 54.38 & 56.58 \\
& 28 & 35 & 5 & 56.21 \\
\hline Control samples & 28 & 30 & - & 46.30 \\
\hline
\end{tabular}

crystallinity. When the other treatment conditions were constant, the crystallinity increased with extension in treatment duration. When treated at the same temperature for the same duration, the crystallinity of the wood samples increased slightly with an increase in ammonia concentration. Finally, under treatment with the same ammonia concentration for the same duration, the crystallinity of the ammonia-fumigated samples increased with increasing temperature. Overall, ammonia fumigation treatment increased the crystallinity of the treated wood, indicating that ammonia causes a positive degree of crystallinity.
3.4. DMA Analysis. Figure 6 shows the measured storage modulus and loss modulus of the wood samples treated with different temperatures and ammonia concentrations for different durations. Figure 6(a) shows that the storage modulus of the samples treated at different temperatures in $28 \%$ ammonia solution decreased with increasing treatment temperature. This is because the kinetic energy of the wood molecules is low under low-temperature conditions. When external force is applied, various functional groups such as side groups, branching chains, and main chains can move. Therefore, the storage modulus is large [12]. When the temperature rises, the molecular motion gradually increases, and 


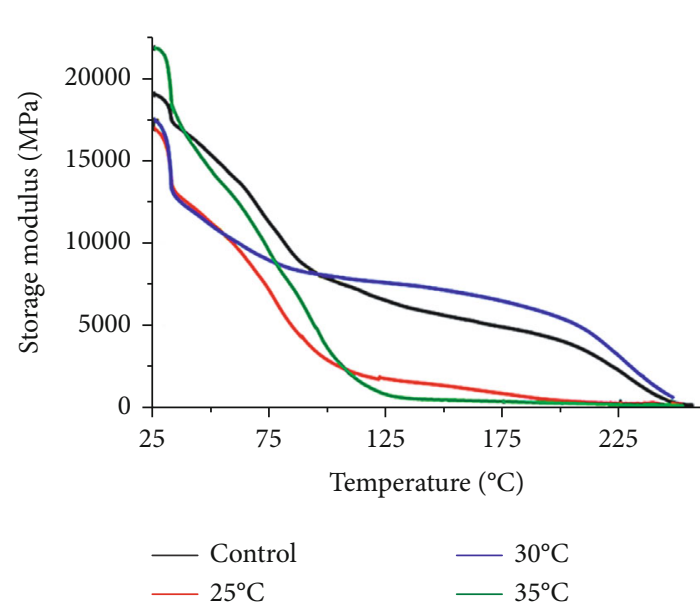

(a)

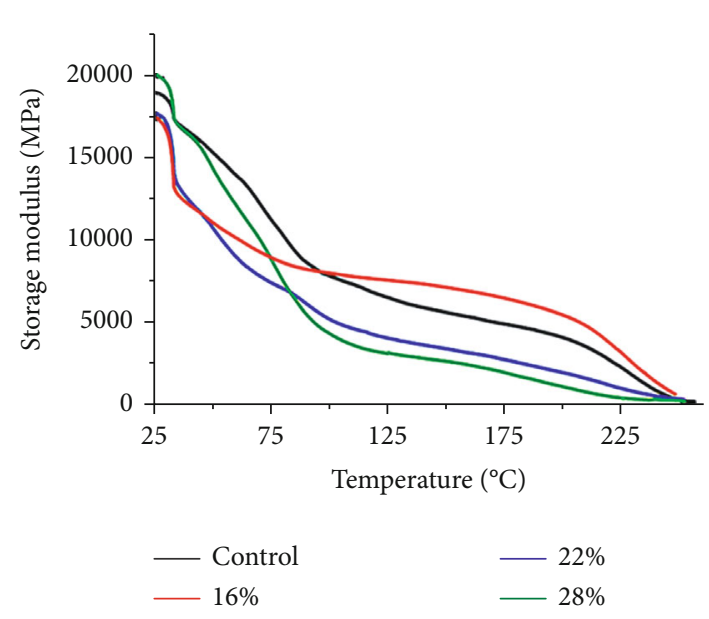

(c)

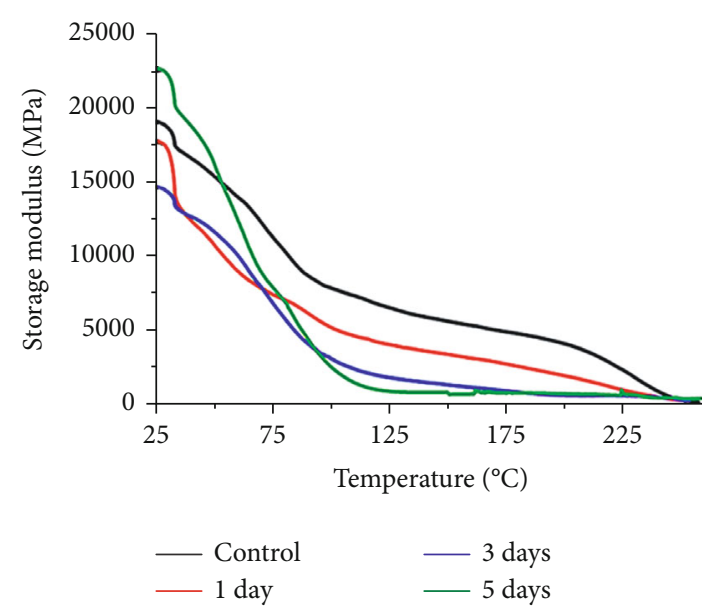

(e)
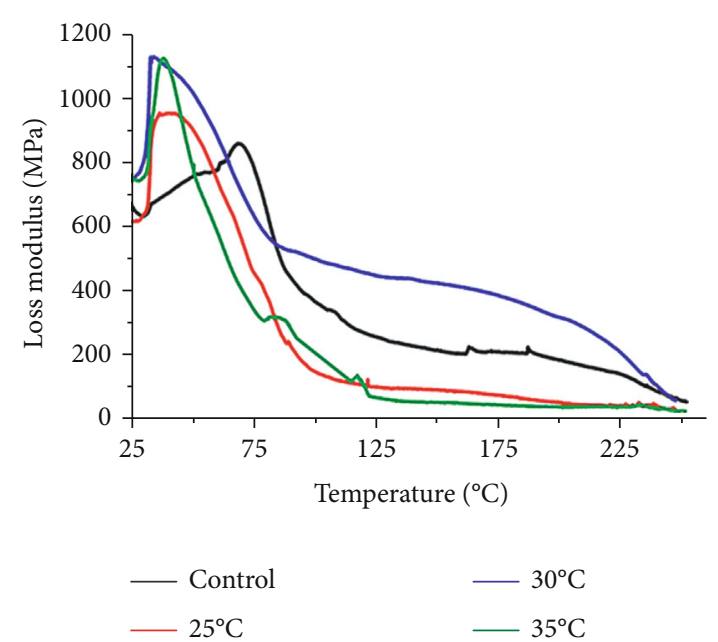

(b)

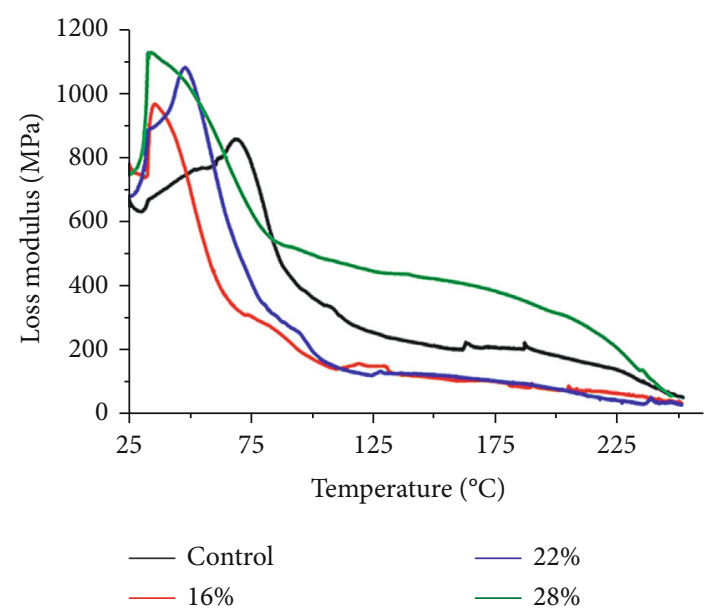

(d)

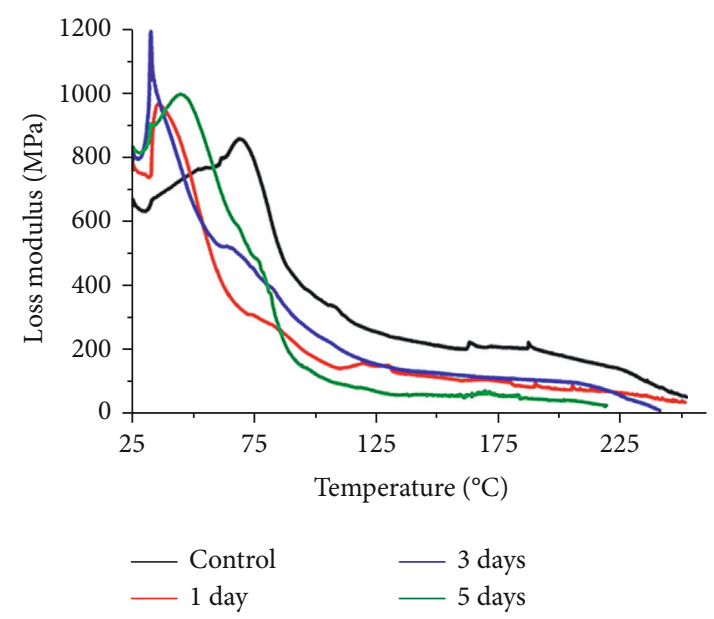

(f)

Figure 6: DMA curves of treated samples. (a) Storage modulus and (b) loss modulus of samples fumigated at different temperatures (25$35^{\circ} \mathrm{C}$ ); (c) storage modulus and (d) loss modulus of samples fumigated with different ammonia concentrations (16-28\%); (e) storage modulus and (f) loss modulus of samples fumigated for different durations (1-5 days).

the storage modulus gradually decreases. The storage modulus of the ammonia-fumigated wood was lower than that of the control wood. The main reason for this is that polar ammonia molecules swell the noncrystalline areas of the wood cellulose, hemicellulose, and lignin during ammonia fumigation treatment. This increases the free movement 
space of the molecules. At the same time, the increase in temperature provides the molecules with enough energy to promote the glass transition of hemicellulose and lignin, thereby enhancing the movement of wood molecules.

The loss modulus of the wood samples decreased with increasing treatment temperature. Compared with that of the control samples, the loss modulus of the ammoniafumigated samples was reduced. The plasticity of the wood decreased upon ammonia fumigation treatment, while thermal softening of the lignin and hemicellulose molecules occurred, causing viscoelastic changes to the wood. This demonstrates that ammonia fumigation has an effect on the chemical composition of wood. An $\alpha$ relaxation peak appears in the loss modulus at a temperature of $30-60^{\circ} \mathrm{C}$. After ammonia fumigation treatment, the relaxation peak of the material gradually occurs at a lower temperature (from 73 to $32.5-55.6^{\circ} \mathrm{C}$ ), while the intensity of the relaxation peak increases. This indicates that the internal binding force in the amorphous region of the material decreases, and the reduction of the intermolecular force is prone to relaxation [13]. Figures 6(c)-6(f) show that as the ammonia concentration and fumigation duration increased, the storage modulus reduced, the loss modulus increased, the plasticity increased, and the elasticity decreased. These changes are beneficial for improving the dimensional stability of the wood.

3.5. FTIR Spectroscopy. Figure 7 shows the FTIR spectra of the ammonia-fumigated wood samples treated at 25,30 , or $35^{\circ} \mathrm{C}$ with an ammonia concentration of $28 \%$ and treatment duration of 3 days, whereas Figure 8 shows the FTIR spectra of samples treated at $30^{\circ} \mathrm{C}$ with an ammonia concentration of $22 \%$ and treatment duration of 1,3 , or 5 days.

As shown in Figure 7, the absorption peak at $3,443 \mathrm{~cm}^{-1}$ of the ammonia-fumigated wood treated at different temperatures was reduced compared with that of the control wood. This indicates that the ammonia fumigation treatment reduces the hydroxyl content of the wood. The number of free hydroxyl groups in the amorphous cellulose region decreases and the crystallinity of the wood increases [5]. The 2,250-2,340 $\mathrm{cm}^{-1}$ band of the ammonia-fumigated material indicated that it might be a compound containing triple bonds or cumulative double bonds. The absorption peak at $2,120 \mathrm{~cm}^{-1}$ corresponds to the external standard, potassium bromide [14]. The intensity of the absorption peak of the nonconjugated carbonyl group at $1,500-1,735 \mathrm{~cm}^{-1}$ decreased, characterizing the relative decrease in hemicellulose content, and the absorption peak of the alcoholic hydroxyl group at $1,271 \mathrm{~cm}^{-1}$ reduced. Thus, the numbers of hydroxyl and carboxyl groups on the main chain and side chain of hemicellulose were reduced. Therefore, there was a reaction between ammonia and hemicellulose that reduced the hemicellulose content. The lignin benzene ring structure vibration at $1,602 \mathrm{~cm}^{-1}$ was significantly reduced, indicating that the lignin content decreased. The peak at $1,086 \mathrm{~cm}^{-1}$ corresponded to the $\mathrm{C}-\mathrm{O}$ stretching vibration of secondary lignin alcohols and aliphatic ethers. Carbonyl, carboxyl, and hydroxyl groups, as well as carbon-carbon double bonds, are the main chromophoric groups and auxochromic groups

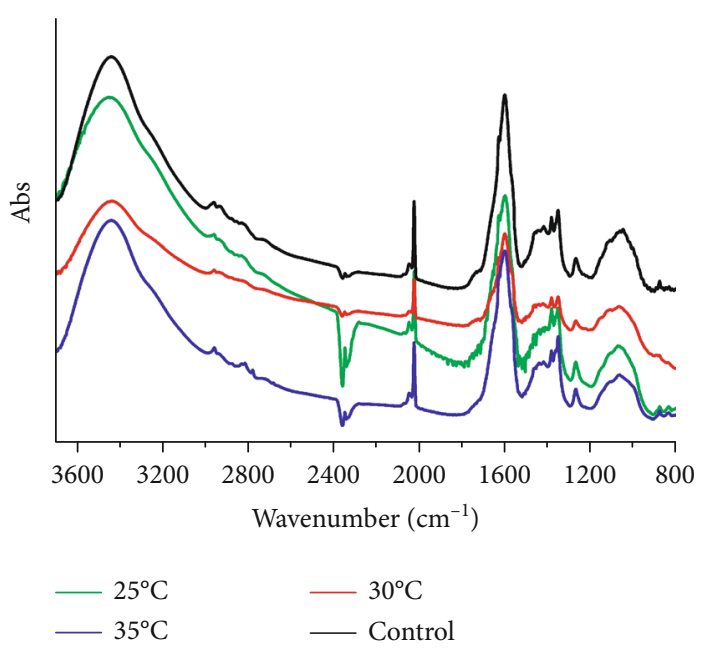

FIGURE 7: FTIR spectra of ammonia-fumigated samples treated at different temperatures.

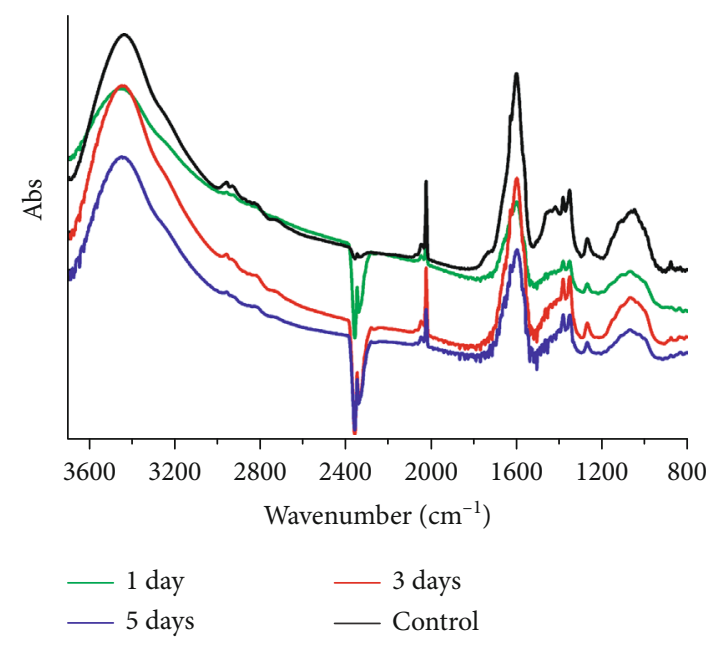

FIGURE 8: FTIR spectra of ammonia-fumigated samples treated for different durations.

in wood, which are present in lignin and extracts. Therefore, ammonia gas may react with wood extracts [15]. From the analysis of the absorption peak absorbance, it was clear that the intensity of the absorption peaks decreased as the temperature of the ammonia fumigation treatment increased. This might be due to the increase in moisture in the air due to the increase in temperature, which reduced the density of ammonia molecules and the wood ammonia fumigation effect.

Figure 8 shows that the intensity of the characteristic peak at $3,000-3,750 \mathrm{~cm}^{-1}$ decreased slightly with the ammonia fumigation duration. This is due to multiple factors, including the low concentration of ammonia fumigation and ammonia fumigation water molecules. The reduction in hydroxyl groups was reduced, indicating that treatment duration had little effect on the performance of the ammonia fumigation. Nevertheless, the ammonia fumigation treatment duration had a significant effect on the 2,250$2,340 \mathrm{~cm}^{-1}$ region band. 
In summary, after ammonia fumigation treatment, the content of carbonyl and hydroxyl groups in the wood decreased, and the number of hydrophilic hydroxyl and carbonyl groups decreased. This reduced the surface wettability and increased the contact angle. As the ammonia fumigation temperature increased, the reaction between the ammonia gas and hemicellulose or lignin increased.

\section{Conclusions}

In this study, a single factor experiment was used to determine the effect of the ammonia concentration, fumigation temperature, and fumigation duration on the color, surface wettability, dynamic viscoelasticity, and chemical composition of $B$. alnoides wood samples. The main conclusions are as follows:

(1) Compared with control wood, the color of the ammonia-fumigated wood changed significantly. The color difference increased with the treatment duration, ammonia concentration, and treatment temperature. Among them, the influence of ammonia concentration on color difference is more significant than that of treatment temperature

(2) With an increase in the ammonia concentration and treatment duration, the surface contact angle of the ammonia-fumigated samples increased. The longer the treatment, the smaller the difference in contact angle. After 5 days of ammonia fumigation, the contact angle was approximately $77^{\circ}$

(3) Compared with control wood, the crystallinity of wood increased after ammonia fumigation treatment. The crystallinity of wood increased with the treatment duration, while the ammonia concentration and treatment temperature had a negligible influence on crystallinity

(4) The storage modulus and loss modulus of ammoniafumigated samples decreased with increasing measurement temperature. The storage modulus and loss modulus were both lower than those of the control sample, indicating that the ammonia fumigation treatment has an impact on the chemical composition of the wood. The greater the ammonia concentration during fumigation and the longer the treatment duration, the smaller the storage modulus of the ammonia-fumigated material, and the greater the loss modulus

(5) FTIR spectroscopy demonstrated that there was a reduction in hydrophilic groups such as hydroxyl and carboxyl groups in the ammonia-fumigated samples compared with the control sample. Chemical reactions occur between the ammonia and lignin and extracts in the wood during the ammonia fumigation process. The chromophoric and auxochromic groups, such as carbonyl, carboxyl, and hydroxyl groups, are also affected by the fumigation process

\section{Data Availability}

The data used to support the findings of this study are available from the corresponding author upon request.

\section{Conflicts of Interest}

The authors declare that they have no conflicts of interest.

\section{Acknowledgments}

The authors appreciate the financial support from the Zhejiang Provincial Natural Science Foundation of China (LY19C160004 and LQ20C160001) and the National Key Research and Development Program of China (2017YFD0601105).

\section{References}

[1] A. Geng, H. Zhang, and H. Yang, "Greenhouse gas reduction and cost efficiency of using wood flooring as an alternative to ceramic tile: a case study in China," Journal of Cleaner Production, vol. 166, pp. 438-448, 2017.

[2] X. Yu, D. Xu, Y. Sun et al., "Preparation of wood-based panel composites with poplar veneer as the surface layer modified by in-situ polymerization of active monomers," Forests, vol. 11, no. 8, p. 893, 2020.

[3] W. B. Wei, L. N. Li, C. He, X. Liu, M. Z. Feng, and S. B. Zhang, "Antique wood flooring on the feasibility study for CNC machining," in Proceedings of 2012 International Conference on Biobase Material Science and Engineering, Changsha, China, 2012.

[4] M. Weigl, J. Pöckl, and M. Grabner, "Selected properties of gas phase ammonia treated wood," European Journal of Wood and Wood Products, vol. 67, no. 1, pp. 103-109, 2009.

[5] Z. Pawlak and A. S. Pawlak, "A review of infrared spectra from wood and wood components following treatment with liquid ammonia and solvated electrons in liquid ammonia," Applied Spectroscopy Reviews, vol. 32, no. 4, pp. 349-383, 1997.

[6] M. Weigl, J. Pöckl, U. Müller, H. Pretzl, and M. Grabner, "UVresistance of ammonia treated wood," in 3rd European Conference on Wood Modification, Cardiff, UK, 2007.

[7] J. Miklečić, N. Španić, and V. Jirouš-Rajković, "Wood color changes by ammonia fuming," BioResources, vol. 7, no. 3, pp. 3767-3778, 2012.

[8] L. G. Segal, J. J. Creely, A. E. Martin Jr., and C. M. Conrad, “An empirical method for estimating the degree of crystallinity of native cellulose using the X-ray diffractometer," Textile Research Journal, vol. 29, no. 10, pp. 786-794, 1959.

[9] M. Weigl, U. Müller, R. Wimmer, and C. Hansmann, "Ammonia vs. thermally modified timber-comparison of physical and mechanical properties," European Journal of Wood and Wood Products, vol. 70, no. 1-3, pp. 233-239, 2012.

[10] P. Čermák and A. Dejmal, "The effect of heat and ammonia treatment on colour response of oak wood (Quercus robur) and comparison of some physical and mechanical properties," Maderas. Ciencia y tecnología, vol. 15, no. 5, pp. 375-389, 2013.

[11] L. Rosca, R. Puhringer, H. A. Schmidt, and I. L. Tanczos, "New aspects in studying and application of ammonia treatment of 
softwood," in Wood Structure and Properties, pp. 233-239, Arbora Publishers, Zvolen, 2002.

[12] M. D. Stanciu, D. Sova, A. Savin, N. Ilias, and G. A. Gorbacheva, "Physical and mechanical properties of ammoniatreated black locust wood," Polymers, vol. 12, no. 2, p. 377, 2020.

[13] N. Saba and M. Jawaid, "A review on dynamic mechanical properties of natural fibre reinforced polymer composites," Construction and Building Materials, vol. 106, pp. 149-159, 2016.

[14] R. G. Milkey, "Potassium bromide method of infrared sampling," Analytical Chemistry, vol. 30, no. 12, pp. 1931-1933, 1958.

[15] C. Zhao, X. Qiao, Q. Shao, M. Hassan, Z. Ma, and L. Yao, "Synergistic effect of hydrogen peroxide and ammonia on lignin," Industrial Crops and Products, vol. 146, pp. 112-177, 2020. 